\title{
Off-label drug use in pediatric patients: a comparative analysis with nationwide routine prescription data
}

\author{
Narin $\mathrm{Ak}_{111^{1}}{ }^{\oplus}, \mathrm{N}$. İpek Kirmızi ${ }^{2 \oplus}$, Volkan Aydın ${ }^{2 \oplus}$, Banu Bayar ${ }^{3 \oplus}$, Mesil Aksoy $^{3 \oplus}$, \\ Ahmet $\mathrm{AkiCl}^{2 \oplus}$ \\ ${ }^{1}$ Department of Pediatrics, Haydarpasa Numune Training and Research Hospital, İstanbul; ${ }^{2}$ Department of Medical Pharmacology, \\ Marmara University Faculty of Medicine, İstanbul; ${ }^{3}$ Turkish Medicines and Medical Devices Agency, Ministry of Health, Ankara, \\ Turkey.
}

\begin{abstract}
Background. Children constitute a special population for off-label drug use (OLDU), yet limited drug-focused data exist regarding pediatric OLDU in clinical practice. This study aimed to investigate pediatric OLDU practice and compare it with pediatric drug utilization patterns of routine prescribing data.
\end{abstract}

Methods. This cross-sectional study examined all approved pediatric OLDU applications, compared with electronic prescription data on national Prescription Information System of Turkish Medicines and Medical Devices Agency in 2015. OLDU applications and prescriptions were analyzed for demographic characteristics, healthcare/socioeconomic indices as well as details of drugs and diagnoses.

Results. We found 7,896 OLDU applications and 7,029,512 prescriptions for the pediatric population in 2015. OLDU applications and prescriptions were mostly practiced for "2-11-year-old" children $(52.7 \%$ vs. $63.4 \%$, respectively; $\mathrm{p}<0.01)$. OLDU applications and prescriptions were detected to have a positive correlation with socio-economic development index $(r=0.45, p<0.0001$ and $r: 0.40, p=0.0002$; respectively $)$ and the physician density $(r=0.66, p<0.0001$ and $r: 0.43, p<0.0001$; respectively). In addition, OLDU was also positively correlated with the number of hospital beds per province $(r=0.39, p=0.0003)$. Antineoplastic/immunomodulating agents were the most commonly applied drug category in OLDU $(47.0 \%)$, compared with respiratory system drugs $(36.6 \%)$ in routine prescribing. Eculizumab (6.5\%), mycophenolate (5.6\%), and canakinumab (4.4\%) were the top drugs used as off-label. OLDU applications and routine prescription data revealed the most frequent diagnosis as "I27-other pulmonary heart diseases" (7.4\%) and "J06-acute upper respiratory infections" (12.6\%), respectively.

Conclusions. This is the first nationwide study to show indication- and drug-centered aspects of pediatric OLDU and prescribing practice. Though OLDU applications is overall consistent with routine clinical practice in terms of demographics and institutional capacity, substantial variations exist regarding main drug classes and diseases. Our findings are expected to shed light on interventions focused on improving "indicated" pediatric use of drugs currently applied as off-label.

Key words: off-label drug use, children, prescribing, antineoplastic, immunomodulating.

New drug development is a long-term and costly path that requires pre-clinical and clinical efficacy and safety studies. Incorporating all potential indications and target age groups that could benefit from the investigational

\footnotetext{
$凶$ Ahmet Akıc1

aakici@marmara.edu.tr
}

Received 1st October 2019, revised 25th April 2020, accepted 26th April 2020. new drug poses additional burden, further increasing the expenditure and duration. ${ }^{1}$ Therefore, restricting approved indications and age groups of potential novel drug is attempted by conducting clinical trials on somehow standardized populations of healthy/patient volunteers beside ethical, legal, or economic concerns. This pragmatical approach, however, results in limited data of drug use in special groups, such as fragile elderly or children. ${ }^{2,3}$ 
Use of drugs for other than their approved indications, doses, way of administration, age group, or special populations etc. is defined as "off-label drug use (OLDU)" ${ }^{4,5}$ It is more common in several branches of clinical practice, including oncology (85\%), gynecology and obstetrics $(25 \%)$, and pediatrics $(3 \%$ to $90 \%)$. $^{6}$ ${ }_{10}$ An important reason for increased rate of OLDU in pediatrics is that children are usually excluded from clinical phase studies due to above-mentioned reasons. ${ }^{2,11,12}$ In order to make pediatric pharmacotherapy more labelled, further clinical studies need to be performed with designs overcoming potential difficulties pertaining to children. This could be preceded by comprehensive assessments of routine drug utilization patterns. In addition, age groupspecific indications require being reviewed through the evidence arising from systematic evaluation of OLDU experiences in children.

The literature on OLDU seems to be based on rather general off-label use or is focused on special patient subsets, lacking descriptions of a nationwide pediatric OLDU practice compared to routine prescription data. ${ }^{8-10,13-15}$ This study aimed to investigate pediatric OLDU practice and compare it with pediatric drug utilization patterns in routine prescribed data.

\section{Material and Methods}

This cross-sectional study examined approved pediatric OLDU applications and electronic prescription data registered on national Prescription Information System (PIS). OLDU applications were made to Turkish Medicines and Medical Devices Agency (TMMDA) of the Ministry of Health. The agency reviews the applications and records main medical data and its final status on its electronic medium. ${ }^{4}$ PIS, used for examining routine prescription data, mediates several analyses and assessments about electronic prescriptions submitted to the national prescription database. ${ }^{16}$ In this study, all pediatric OLDU applications with the final status of "approved" during year 2015 were analyzed. Routine prescribing was evaluated by the prescriptions in PIS, which were delivered by pediatricians or subspecialists of pediatrics for 18-year-old children. In 2015, the universe of our study, i.e. children, constituted $29.0 \%$ of the total population of 78.7 million inhabitants in Turkey. ${ }^{17}$

OLDU applications/prescriptions were examined with respect to patients' demographics, drugs' Anatomical Therapeutic Chemical (ATC) classification, and International Statistical Classification of Diseases (ICD) category. The latter also included applications/ prescriptions with multiple diagnoses. Pediatric population were stratified as three groups: infants ( $<2$ years old), children $(2-11$ years old), and adolescents ( $\geq 12$ years old). These groups were compared in terms of the number of applications/prescriptions, sex, and the mean age. Furthermore, OLDU applications and prescriptions were analyzed with respect to several regional healthcare utilization parameters (number of hospital beds, number of physicians per 100,000 inhabitants, percentage of child population, number of health service applications to secondary/tertiary centers) and socio-economic development index (SEDI). While data on regional healthcare utilization was obtained from Health Statistics Yearbook 2015 of Turkish Ministry of Health and Turkish Statistics Institute ${ }^{17,18}$, SEDI has 61 items indicating various domains (demographics, employment, health, finance, and quality of life, etc.) that were used for scoring and ranking the provinces, as rigorously calculated by the Turkish Ministry of Development. ${ }^{19}$

The drugs at OLDU applications were compared by age groups at the ATC- 1 level. Furthermore, the top 15 most commonly applied drugs were examined at ATC-5 level. These drugs were also assessed as to whether they fell into a biotechnological or licensed category.

The top three commonly encountered diagnoses in OLDU applications were examined with their top three applied drugs and the applying physicians' specialty. Beside this indicationfocused approach, a drug-focused approach was 
also undertaken to show diagnostic distribution: most frequent three diagnoses and total number of different diagnoses were determined for each of the top ten drugs in OLDU applications. This analysis was performed using applications with only a single diagnosis.

\section{Statistical analysis}

Statistical analyses were made through SPSS 25.0 software. Categorical and continuous variables were expressed as number/percentage and mean/standard deviation, respectively. The comparisons between groups were analyzed via chi-square for categorical and t-test for continuous variables. The associations of number of OLDU applications and prescriptions to regional healthcare utilization parameters and SEDI was tested using Spearman's rank correlation. An overall 5\% type-I error level was used to infer statistical significance.

The data were collected after the study was approved by the Ethics Committee of Institute of Health Science of Marmara University (Approval Date/No: 11.09.2017/171).

\section{Results}

A total of 7,896 pediatric OLDU applications were detected in the one-year study period, during which the number of prescriptions in PIS generated for pediatric population was $7,029,512$ as routine prescribing. The majority of applications/prescriptions in OLDU and routine PIS practice were for the "children" subgroup ( $52.7 \%$ vs $63.4 \%$, respectively; $\mathrm{p}<0.01$ ); followed by adolescents in OLDU (36.1\%) and infants in PIS practice (24.9\%). All comparisons between the age groups in terms of percentage of applications/prescriptions significantly differed from each other ( $p<0.01$, Fig. 1). The mean age of the "age groups" was significantly higher in OLDU applications than that in PIS ( $p<0.01$ for all age groups). The applications/ prescriptions were more likely to be generated for boys over girls in all age groups in both OLDU and PIS database with a tendency to be balanced with increasing age: girls constituted $45.5 \%$ and $45.0 \%$ in infants and $48.4 \%$ and $49.4 \%$ among adolescence in OLDU and PIS database, respectively.

The number of OLDU applications and prescriptions were found to be positively correlated with SEDI $(\mathrm{r}=0.45, \mathrm{p}<0.0001$ and $\mathrm{r}$ $=0.40, \mathrm{p}=0.0002$; respectively), the number of physicians per 100,000 inhabitants $(r=0.66, p$ $<0.0001$ and $\mathrm{r}=0.43, \mathrm{p}<0.0001$; respectively). In addition, OLDU applications were also positively correlated with the number of hospital beds per province $(\mathrm{r}=0.39, \mathrm{p}=0.0003)$.

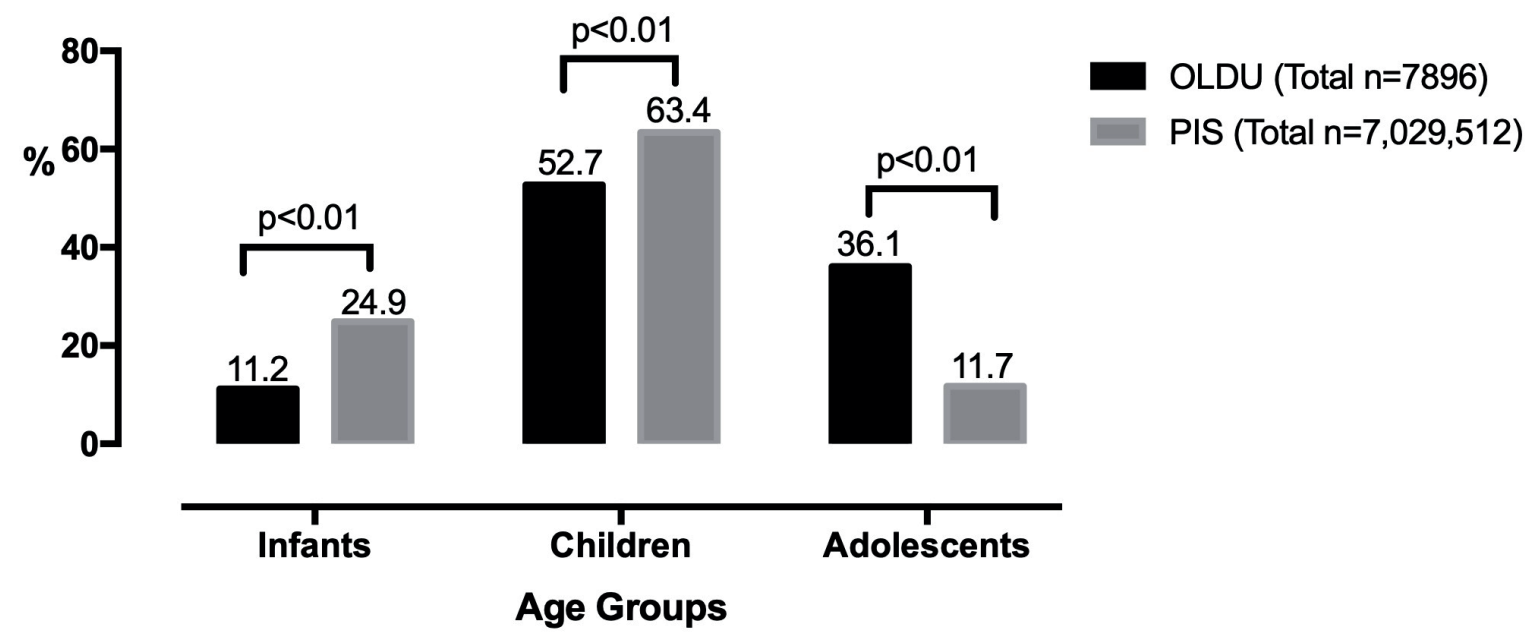

Fig. 1. Comparison of OLDU applications and routine prescribing data on PIS based on the age. groups (OLDU, off-label drug use; PIS, Prescription Information System). 
The number of health service applications or the percentage of child population was not correlated with OLDU applications or routine prescriptions ( $p>0.05$ for each).

OLDU applications showed the most common drug group at ATC-1 level as "antineoplastic and immunomodulating agents" (47.0\%), followed by "blood and blood forming organs" (7.7\%) and "alimentary tract and metabolism" $(7.7 \%)$. On the other hand, the most commonly prescribed drug group in routine practice belonged to "respiratory system" (36.6\%), "anti-infectives for systemic use" (22.9\%) and "alimentary tract and metabolism" (13.4\%), (Fig. 2).

The distribution of drug categories in OLDU applications revealed significant differences between infants, children and adolescents ( $\mathrm{p}<0.05$ ), except "blood and blood forming organs" and "systemic hormonal preparations, excluding sex hormones and insulins" ATC-1 categories (Table I).
A total of 336 different drugs were detected in OLDU applications. The most commonly applied drug was eculizumab (6.5\%), followed by mycophenolate $(5.6 \%)$ and canakinumab $(4.4 \%)$. The most commonly applied offlabel drug by age groups was determined as sapropterin $(16.6 \%)$ in infants, eculizumab $(6.7 \%)$ in children, and mycophenolate (8.0) in adolescents. The top 15 drugs in OLDU applications were found to constitute 50.0\% $(n=3937)$. While eight of these $(53.3 \%)$ were biotechnological drugs overall, stratification by age group showed three $(20.0 \%)$ in infants and eight $(53.3 \%)$ in both children and adolescents. In addition, only two (13.3\%) of these top 15 drugs were found to be unlicensed in Turkey (Table II).

The distribution of diagnoses in OLDU applications revealed 548 different diagnoses with the most frequent group as "I27-other pulmonary heart diseases" (7.4\%), as compared to that in PIS-based routine prescribing as "J06-acute upper respiratory infections"

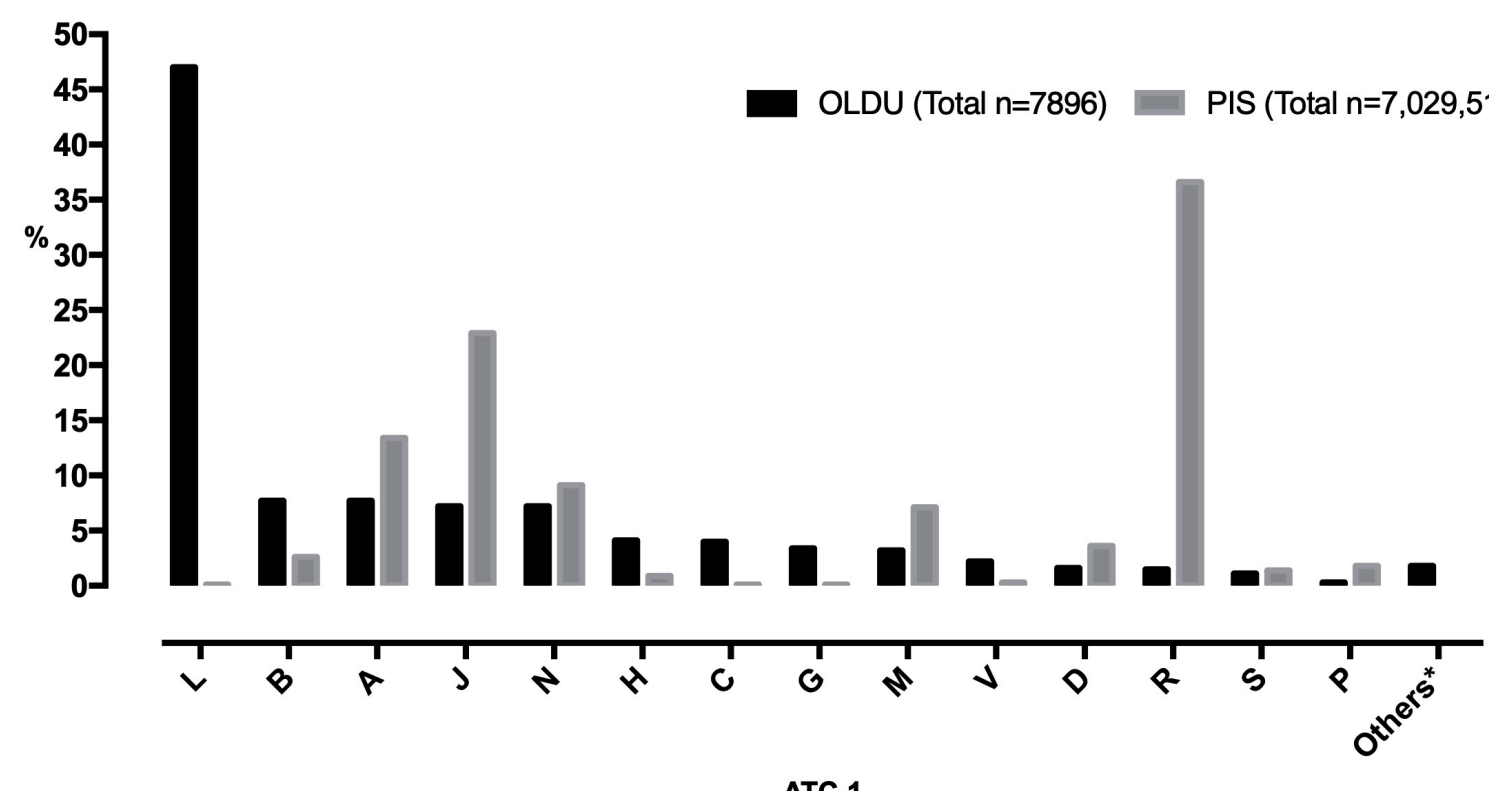

Fig. 2. Distribution of the drugs at OLDU applications and routine prescribing data on PIS by ATC-1 category. (OLDU, off-label drug use; PIS, Prescription Information System; A, Alimentary tract and metabolism; B, Blood and blood forming organs; C, Cardiovascular system; D, Dermatological; G, Genitourinary system and sex hormones; H, Systemic hormonal preparations, excl. sex hormones and insulins; J, Anti-infectives for systemic use; L, Antineoplastic and immunomodulating agents; M, Musculoskeletal system; N, Nervous system; P, Antiparasitic products, insecticides and repellents; R, Respiratory system; S, Sensory organs; V, Various; ${ }^{*}$, Products with no ATC code). 
Table I. Comparison of drugs at ATC-1 level in OLDU applications based on age groups.

\begin{tabular}{|c|c|c|c|c|}
\hline ATC- 1 codes & $\begin{array}{l}\text { Infants } \\
\mathrm{n}(\%)\end{array}$ & $\begin{array}{l}\text { Children } \\
\mathrm{n}(\%)\end{array}$ & $\begin{array}{l}\text { Adolescents } \\
\mathrm{n}(\%)\end{array}$ & P-value \\
\hline L-Antineoplastic and immunomodulating agents & $248(28.2)$ & $1894(45.5)^{*}$ & $1566(54.9)^{\#}$ & $<0.05$ \\
\hline B-Blood and blood forming organs & $66(7.5)$ & $325(7.8)$ & $220(7.8)$ & $>0.05$ \\
\hline A-Alimentary tract and metabolism & $188(21.3)$ & $338(8.1)^{*}$ & $84(2.9)^{\#}$ & $<0.05$ \\
\hline J-Anti-infectives for systemic use & $80(9.1)$ & $301(7.2)$ & $189(6.7)$ & $<0.05$ \\
\hline N-Nervous system & $24(2.7)$ & $382(9.2)^{*}$ & $160(5.6)^{\#}$ & $<0.05$ \\
\hline $\begin{array}{l}\text { H-Systemic hormonal preparations, excl. sex } \\
\text { hormones and insulins }\end{array}$ & $23(2.6)$ & $182(4.4)$ & $121(4.2)$ & $>0.05$ \\
\hline C-Cardiovascular system & $61(6.9)$ & $151(3.6)^{*}$ & $102(3.6)^{*}$ & $<0.05$ \\
\hline G-Genitourinary system and sex hormones & $41(4.6)$ & $103(2.5)^{\S}$ & $122(4.3)$ & $<0.05$ \\
\hline M-Musculoskeletal system & $6(0.7)$ & $148(3.6)^{*}$ & $98(3.4)^{*}$ & $<0.05$ \\
\hline V-Various & $40(4.5)$ & $88(2.1)^{*}$ & $42(1.5)^{*}$ & $<0.05$ \\
\hline D-Dermatologicals & $18(2.0)$ & $82(2.0)$ & $28(1.0)^{\#}$ & $<0.05$ \\
\hline R-Respiratory system & $31(3.5)$ & $43(1.0)^{*}$ & $45(1.6)^{\#}$ & $<0.05$ \\
\hline S-Sensory organs & $23(2.6)$ & $27(0.6)^{*}$ & $38(1.3)^{\#}$ & $<0.05$ \\
\hline P-Antiparasitic products, insecticides and repellents & $11(1.2)$ & $8(0.2)^{*}$ & $7(0.2)^{*}$ & $<0.05$ \\
\hline Products with no ATC code & $23(2.6)$ & $91(2.2)$ & $28(1.0)^{\#}$ & $<0.05$ \\
\hline Total & $883(100.0)$ & $4163(100.0)$ & $2850(100.0)$ & \\
\hline
\end{tabular}

${ }^{*} \mathrm{p}<0.05$ vs. infants; ${ }^{\mathrm{p}} \mathrm{p}<0.05$ vs. both infants and children; ${ }^{\circledR} \mathrm{p}<0.05$ vs. both infants and adolescents

OLDU: off-label drug use.

Table II. Distribution of drugs at ATC-5 level in OLDU applications based on age groups.

\begin{tabular}{|c|c|c|c|c|}
\hline Rank & All age groups, (\%) & Infants, $(\%)$ & Children, $(\%)$ & Adolescents, $(\%)$ \\
\hline 1 & Eculizumab*, (6.5) & Sapropterin, (16.6) & Eculizumab*, (6.7) & Mycophenolate, (8.0) \\
\hline 2 & Mycophenolate, (5.6) & Eculizumab*, (11.3) & Mycophenolate, (5.0) & Rituximab*, (6.1) \\
\hline 3 & Canakinumab*, (4.4) & Sirolimus, (4.0) & Iloprost, (4.5) & Canakinumab*, (5.6) \\
\hline 4 & Iloprost, (4.3) & Valganciclovir, (3.3) & Sirolimus, (4.3) & Eculizumab*, (4.7) \\
\hline 5 & Rituximab*, (4.1) & Dextromethorphan, (2.9) & Canakinumab*, (4.2) & Iloprost, (4.5) \\
\hline 6 & Sirolimus, (3.8) & Sildenafil, (2.8) & Lacosamide, (3.9) & IVIG $^{*},(3.3)$ \\
\hline 7 & Sapropterin, (3.4) & Bosentan, (2.7) & Adalimumab*, (3.3) & Anakinra*\#, (3.3) \\
\hline 8 & Lacosamide, (2.9) & Iloprost, (2.6) & Rituximab*, (3.2) & Sirolimus, (3.1) \\
\hline 9 & $\mathrm{IVIG}^{*},(2.8)$ & Ranibizumab*, (2.4) & Somatropin*, (3.1) & Adalimumab*, (2.6) \\
\hline 10 & Anakinra*\#, (2.7) & Propranolol, (2.3) & Sapropterin, (2.8) & Somatropin*, (2.3) \\
\hline 11 & Adalimumab*, (2.7) & Calcium folinate, (2.3) & $\mathrm{IVIG}^{*},(2.7)$ & Infliximab*, (2.1) \\
\hline 12 & Somatropin*, (2.6) & Isotretinoin, (1.9) & Anakinra*\#, (2.6) & Lacosamide, (1.9) \\
\hline 13 & Sildenafil, (1.4) & Imatinib, (1.8) & Elosulfase alfa*\#, (2.0) & Tacrolimus, (1.7) \\
\hline 14 & Tacrolimus, (1.4) & $\mathrm{IVIG}^{*},(1.7)$ & Botulinum toxin, (1.4) & Botulinum toxin, (1.6) \\
\hline 15 & Elosulfase alfa*\#, (1.4) & Foscarnet\#, (1.6) & Tacrolimus, (1.4) & Testosterone, (1.6) \\
\hline Others n, $(\%)$ & $3959,(50.0)$ & $578,(39.8)$ & $2029,(48.9)$ & $1353,(47.6)$ \\
\hline Total n, $(\%)$ & $7896,(100.0)$ & $883,(100.0)$ & $4163,(100.0)$ & $2850,(100.0)$ \\
\hline
\end{tabular}

*Biotechnological drugs; \# Unlicensed drugs in Turkey.

OLDU: off-label drug use, IVIG: intravenous immunoglobulin. 
(12.6\%). Among the top 15 diagnoses of OLDU applications, three belonged to "E-endocrine, nutritional and metabolic diseases" $(22.2 \%)$ and other three belonged to " $\mathrm{D}$-diseases of the blood and blood-forming organs and certain disorders involving the immune mechanism" (18.8\%) main ICD categories. On the other hand, ten out of 15 top diagnosis belonged to "J-diseases of respiratory system" $(82.4 \%)$ category in routine prescribing (Table III).

The most commonly applied diagnosis for pediatric OLDU was epilepsy (G40), for which the most commonly requested off-label drug was lacosamide $(42.4 \%)$ by mostly pediatric neurologists $(92.4 \%)$. The second most common

Table III. Distribution of diagnoses in OLDU applications and routine prescribing on PIS.

\begin{tabular}{|c|c|c|c|c|}
\hline \multirow{2}{*}{ Rank } & \multicolumn{2}{|l|}{ OLDU applications } & \multicolumn{2}{|l|}{ PIS prescriptions } \\
\hline & Diagnosis & $\mathrm{n}(\%)$ & Diagnosis & $\mathrm{n}(\%)$ \\
\hline 1 & I27_Other pulmonary heart diseases & $\begin{array}{l}592 \\
(7.4)\end{array}$ & $\begin{array}{l}\text { J06_Acute upper respiratory infections of } \\
\text { multiple and unspecified sites }\end{array}$ & $\begin{array}{c}1,105,753 \\
(12.6)\end{array}$ \\
\hline 2 & G40_Epilepsy & $\begin{array}{l}537 \\
(6.7)\end{array}$ & J02_Acute pharyngitis & $\begin{array}{c}887,111 \\
(10.1)\end{array}$ \\
\hline 3 & D59_Acquired haemolytic anaemia & $\begin{array}{l}496 \\
(6.2)\end{array}$ & J03_Acute tonsillitis & $\begin{array}{c}832,465 \\
(9.5)\end{array}$ \\
\hline 4 & N04_Nephrotic syndrome & $\begin{array}{l}390 \\
(4.9)\end{array}$ & J20_Acute bronchitis & $\begin{array}{c}408,156 \\
(4.6)\end{array}$ \\
\hline 5 & E85_Amyloidosis & $\begin{array}{l}388 \\
(4.8)\end{array}$ & $\begin{array}{l}\text { J00_Acute nasopharyngitis [common } \\
\text { cold] }\end{array}$ & $\begin{array}{c}406,688 \\
(4.6)\end{array}$ \\
\hline 6 & $\begin{array}{l}\text { E70_Disorders of aromatic amino-acid } \\
\text { metabolism }\end{array}$ & $\begin{array}{l}349 \\
(4.3)\end{array}$ & $\begin{array}{l}\text { K52_Other noninfective gastroenteritis } \\
\text { and colitis }\end{array}$ & $\begin{array}{c}297,534 \\
(3.4)\end{array}$ \\
\hline 7 & M08_Juvenile arthritis & $\begin{array}{l}319 \\
(4.0)\end{array}$ & J21_Acute bronchiolitis & $\begin{array}{c}291,426 \\
(3.3)\end{array}$ \\
\hline 8 & $\begin{array}{l}\text { E23_Hypofunction and other disorders } \\
\text { of pituitary gland, }\end{array}$ & $\begin{array}{c}221 \\
(2.8)\end{array}$ & J45_Asthma & $\begin{array}{l}254,218 \\
(2.9)\end{array}$ \\
\hline 9 & $\begin{array}{l}\text { D69_Purpura and other haemorrhagic } \\
\text { conditions }\end{array}$ & $\begin{array}{l}166 \\
(2.1)\end{array}$ & $\begin{array}{l}\text { J39_Other diseases of upper respiratory } \\
\text { tract }\end{array}$ & $\begin{array}{l}240,556 \\
(2.7)\end{array}$ \\
\hline 10 & $\begin{array}{l}\text { T86_Failure and rejection of } \\
\text { transplanted organs and tissues }\end{array}$ & $\begin{array}{l}164 \\
(2.0)\end{array}$ & J30_Vasomotor and allergic rhinitis & $\begin{array}{c}232,309 \\
(2.6)\end{array}$ \\
\hline 11 & C91_Lymphoid leukaemia & $\begin{array}{l}146 \\
(1.8)\end{array}$ & J01_Acute sinusitis & $\begin{array}{c}218,139 \\
(2.5)\end{array}$ \\
\hline 12 & $\begin{array}{l}\text { D18_Haemangioma and } \\
\text { lymphangioma, any site }\end{array}$ & $\begin{array}{l}146 \\
(1.8)\end{array}$ & L30_Other dermatitis & $\begin{array}{c}216,021 \\
(2.5)\end{array}$ \\
\hline 13 & B25_Cytomegaloviral disease & $\begin{array}{l}142 \\
(1.8)\end{array}$ & R10_Abdominal and pelvic pain & $\begin{array}{c}202,737 \\
(2.3)\end{array}$ \\
\hline 14 & $\begin{array}{l}\text { C74_Malignant neoplasm of adrenal } \\
\text { gland }\end{array}$ & $\begin{array}{l}139 \\
(1.7)\end{array}$ & D64_Other anaemias & $\begin{array}{c}173,984 \\
(2.0)\end{array}$ \\
\hline 15 & G80_Cerebral palsy & $\begin{array}{c}112 \\
(1.4)\end{array}$ & $\begin{array}{l}\text { Z00_General examination and } \\
\text { investigation of persons without } \\
\text { complaint and reported diagnosis }\end{array}$ & $\begin{array}{c}153,660 \\
(1.7)\end{array}$ \\
\hline & Others & $\begin{array}{l}3718 \\
(46.3) \\
\end{array}$ & Others & $\begin{array}{c}2,886,872 \\
(32.8) \\
\end{array}$ \\
\hline & Total & $\begin{array}{c}8025 \\
(100.0)\end{array}$ & Total & $\begin{array}{c}8,807,629 \\
(100.0)\end{array}$ \\
\hline
\end{tabular}

OLDU: off-label drug use, PIS: Prescription Information System. 
diagnosis was "other secondary pulmonary hypertension (I27.2)" where more than half (56.2\%) included iloprost for OLDU near always by pediatric cardiologists (99.6\%). "Hemolytic uremic syndrome (HUS) (D59.3)" was the third indication, for which eculizumab constituted near all applications $(99.1 \%$ ) by mostly pediatric rheumatologists/nephrologists (93.1\%), (Table IV).

Drug-centered analysis for diagnoses in OLDU applications showed eculizumab to be mostly requested for HUS (86.4\%), mycophenolate for nephrotic syndrome (35.8\%), and canakinumab for amyloidosis $(66.2 \%)$, (Table V).

\section{Discussion}

This study examined an exclusive practice of drug use in pediatrics, as off-label, and we described close to eight thousand OLDU applications all over the country, compared to routine prescribing from several aspects. It appears that OLDU shared several characteristics of routine prescribing practice such as sex, health/socio-economic indicators, or partially age group distribution, however it substantially differed in terms of drug and disease spectrum.

A major contribution to OLDU applications came from the children (2 to 11-year-old) group in routine prescribing. Though lower than the latter, the percentage of this age group in all pediatric OLDU applications (52.7\%) seemed to comparably reflect the share of this age group $(49.6 \%)$ within the pediatric population in $2015 .^{20}$ The distinguishing feature of OLDU in terms of age distribution was that adolescents dominated infants, which was the inverse in routine prescribing. This brings the possibility of delayed recognition of conditions that could require OLDU in early periods of life. In fact, OLDU practice was reported to be more frequent at younger ages, including newborns. ${ }^{14,21}$ However, the distribution of OLDU applications by age groups in our study appears to be very similar to that of the corresponding age groups reported in the normal population. ${ }^{20}$ Therefore, the difference between OLDU and routine prescription in terms of age groups is likely to result from the nature of the latter. While OLDU is a physician-driven practice, the key trigger in routine prescribing is patients' health-seeking behavior, which may account for increased representation of infants. In fact, health-seeking behavior in parents of <1-year-old children was reported to be about seven-fold of that in parents of 1 to 5 -year old children. ${ }^{22}$

OLDU applications or routine prescribing were reported to be influenced by several factors, including regional variations, inhabitant's distribution, and institutional

Table IV. Distribution of mostly encountered diagnoses in OLDU applications with requested drugs and applying physician specialties.

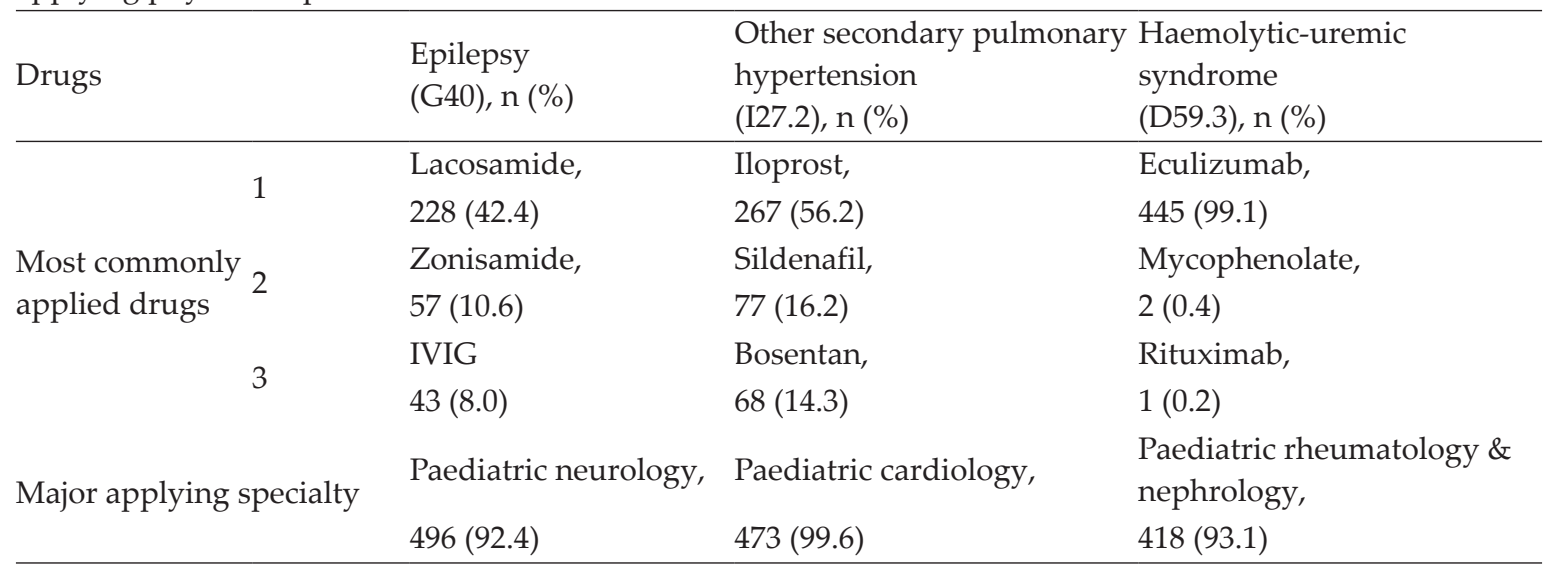

OLDU: off-label drug use, IVIG: intravenous immunoglobulin. 
Table V. Distribution of top ten drugs used as off-label with their frequent diagnoses and diagnostic variation.

\begin{tabular}{|c|c|c|c|c|}
\hline Drug, (n) & $\begin{array}{l}\text { Most frequent } \\
\text { diagnosis, n (\%) }\end{array}$ & $\begin{array}{l}\text { Second most frequent } \\
\text { diagnosis, } \mathrm{n}(\%)\end{array}$ & $\begin{array}{l}\text { Third most frequent } \\
\text { diagnosis, } \mathrm{n}(\%)\end{array}$ & $\begin{array}{c}\text { Total number } \\
\text { of different } \\
\text { diagnoses, } \mathrm{n}\end{array}$ \\
\hline $\begin{array}{l}\text { Eculizumab, } \\
\text { (515) }\end{array}$ & $\begin{array}{l}\text { Haemolytic-uremic } \\
\text { syndrome, } 445(86.4)\end{array}$ & $\begin{array}{l}\text { Unspecified nephritic } \\
\text { syndrome: diffuse } \\
\text { mesangiocapillary } \\
\text { glomerulonephritis, } 27 \text { (5.2) }\end{array}$ & $\begin{array}{l}\text { Paroxysmal nocturnal } \\
\text { haemoglobinuria, } 19 \text { (3.7) }\end{array}$ & 10 \\
\hline $\begin{array}{l}\text { Mycophenolate, } \\
(439)\end{array}$ & $\begin{array}{l}\text { Nephrotic syndrome, } \\
157 \text { (35.8) }\end{array}$ & $\begin{array}{l}\text { Systemic lupus } \\
\text { erythematosus, } 42 \text { (9.6) }\end{array}$ & $\begin{array}{l}\text { Idiopathic } \\
\text { thrombocytopenic } \\
\text { purpura, } 38(8.7)\end{array}$ & 42 \\
\hline $\begin{array}{l}\text { Canakinumab, } \\
\text { (347) }\end{array}$ & $\begin{array}{l}\text { Amyloidosis, } 230 \\
(66.3)\end{array}$ & $\begin{array}{l}\text { Juvenile arthritis with } \\
\text { systemic onset, } 83(24.0)\end{array}$ & $\begin{array}{l}\text { Juvenile rheumatoid } \\
\text { arthritis, } 12 \text { (3.5) }\end{array}$ & 8 \\
\hline Iloprost, (336) & $\begin{array}{l}\text { Other secondary } \\
\text { pulmonary } \\
\text { hypertension, } 267 \\
(79.5)\end{array}$ & $\begin{array}{l}\text { Primary pulmonary } \\
\text { hypertension, } 64 \text { (19.0) }\end{array}$ & $\begin{array}{l}\text { Dilated cardiomyopathy, } \\
3(0.9)\end{array}$ & 5 \\
\hline Rituximab, (318) & $\begin{array}{l}\text { Nephrotic syndrome, } \\
74 \text { (23.3) }\end{array}$ & $\begin{array}{l}\text { Idiopathic thrombocytopenic } \\
\text { purpura, } 28(8.8)\end{array}$ & $\begin{array}{l}\text { Systemic lupus } \\
\text { erythematosus, } 18 \text { (5.7) }\end{array}$ & 57 \\
\hline Sirolimus, (303) & $\begin{array}{l}\text { Haemangioma, any } \\
\text { site, } 55 \text { (18.2) }\end{array}$ & $\begin{array}{l}\text { Other congenital } \\
\text { malformations of circulatory } \\
\text { system, } 48(15.2)\end{array}$ & $\begin{array}{l}\text { Lymphangioma, any site, } \\
45 \text { (14.9) }\end{array}$ & 37 \\
\hline $\begin{array}{l}\text { Sapropterin, } \\
(266)\end{array}$ & $\begin{array}{l}\text { Classical } \\
\text { phenylketonuria, } 198 \\
(74.4)\end{array}$ & $\begin{array}{l}\text { Other } \\
\text { hyperphenylalaninaemias, } 65 \\
(24.4)\end{array}$ & $\begin{array}{l}\text { Disorders of aromatic } \\
\text { amino-acid metabolism, } \\
2(0.8)\end{array}$ & 4 \\
\hline $\begin{array}{l}\text { Lacosamide, } \\
(228)\end{array}$ & Epilepsy, 227 (99.6) & $\begin{array}{l}\text { Other generalized epilepsy } \\
\text { and epileptic syndromes, } 1 \\
(0.4)\end{array}$ & - & 2 \\
\hline IVIG, (221) & Epilepsy, 43 (19.5) & $\begin{array}{l}\text { Immunodeficiency with } \\
\text { predominantly antibody } \\
\text { defects, } 31 \text { (14.0) }\end{array}$ & $\begin{array}{l}\text { Kidney transplant failure } \\
\text { and rejection, } 26 \text { (11.8) }\end{array}$ & 49 \\
\hline Anakinra, (217) & $\begin{array}{l}\text { Amyloidosis, } 130 \\
(59.9)\end{array}$ & $\begin{array}{l}\text { Juvenile arthritis with } \\
\text { systemic onset, } 62 \text { (28.6) }\end{array}$ & $\begin{array}{l}\text { Juvenile rheumatoid } \\
\text { arthritis, } 15 \text { (6.9) }\end{array}$ & 10 \\
\hline
\end{tabular}

OLDU: off-label drug use, IVIG: intravenous immunoglobulin.

infrastructure. ${ }^{23-25}$ OLDU practice was reported as more common in the provinces with high numbers of physicians and secondary/tertiary institutions. ${ }^{24}$ On the other hand, prescribing studies reported association of drug utilization to some regional characteristics such as socioeconomic indicators, number of physicians, or percentage of young population. ${ }^{23,25}$ These seem to be consistent with our findings, showing positive correlation of OLDU applications and routine prescriptions to regional healthcare utilization and socio-economic indicators. The mere difference between OLDU and prescribing practice was the positive association between OLDU and the number of hospital beds. This might be attributed to the fact that OLDU is more likely to be applied from secondary/ tertiary healthcare institutions, as a recent nationwide study in Turkey reported that $81 \%$ of all applications for OLDU were submitted from university hospitals. ${ }^{26}$

Our study showed comparably lower rates of off-label biotechnological drugs in infants. While efficacy/safety data on biotechnological drugs is already scarce in the overall pediatric population, this difference between the age 
groups might be explained by increased recognizability of some diseases with increasing age. For instance, several chronic inflammatory conditions such as juvenile idiopathic arthritis, inflammatory bowel diseases, or endemic familial Mediterranean fever was reported to be more prevalent with increasing age in children. ${ }^{27,28}$ This was further supported by our findings that showed higher off-label use for canakinumab, adalimumab, rituximab, anakinra, and infliximab -typical biologicals for the abovementioned conditions- in children and adolescent age groups compared to that in infants.

Routine prescribing demonstrated predominance of respiratory diseases along with drugs of respiratory system and systemic anti-infectives, consistent with the literature. ${ }^{29-32}$ On the contrary, near half of the drugs (47.0\%) applied for pediatric OLDU was antineoplastic/immunomodulating agents. The most frequently applied drug, eculizumab, is a monoclonal complement C5 antibody, ${ }^{33}$ and the first novel anti-complement therapy in HUS characterized by complement alternative pathway dysregulation. ${ }^{34} \mathrm{~A}$ recent study in France reported close to $80 \%$ of off-label eculizumab use was due to hemolytic anemias including HUS. ${ }^{35}$ In our study, it was also the third most common diagnosis among OLDU applications and responsible for $>85 \%$ of offlabel eculizumab use. Meanwhile, the drug acquired approval towards the end of this study period in October 2015 and started to be used as labelled. ${ }^{36}$

Mycophenolate, the second most common reason for our pediatric OLDU applications, is an immunosuppressive approved in posttransplant patients in many countries including Turkey. ${ }^{37,38}$ In our study, being among the top two applied drugs particularly in children and adolescent groups, mycophenolate was used for nephrotic syndrome over one-third of applications. A systematic review regarding off-label use of mycophenolate reported that nephrotic syndrome constituted ten out of 41 studies with beneficial effects. ${ }^{39}$ Off-label use in this indication might be attributed to its comparably lesser toxicity over other currently used immunosuppressive agents like cyclosporin A or cyclophosphamide. ${ }^{40,41}$ Furthermore, the fact that its off-label use was requested for 42 different diagnoses including systemic lupus and thrombocytopenic purpura inourstudy indicatestheneed formycophenolate as an alternative immunosuppressive drug in children. Rituximab was one of such drugs that were applied for a variety of diagnoses ( 57 out of the 548 different diagnoses in total) in our study, particularly in adolescent and child groups. It was reported to have promising results in children with immunosuppressive-refractory nephrotic syndrome or those suffering from serious adverse effects, ${ }^{42}$ which may explain its preference as a therapeutic alternative for different conditions. In fact, a Spanish study performed in adults reported off-label use of rituximab in 17 different autoimmune conditions, $55 \%$ of which were systemic lupus erythematosus. ${ }^{43}$ In addition, reports from several recent studies on rituximab's efficacy on nephrotic syndrome ${ }^{44,45}$ suggest that off-label experience in pediatrics could constitute a base for such use in adults.

The only nervous system drug among the top ten OLDU applications was lacosamide, approved by the FDA for partial epilepsy in $\geq 16$-year-old children in 2008 and $\geq 4$-year-old in 2017. ${ }^{46}$ In Turkey, it is still only approved for $\geq 16$ years of age and above. ${ }^{47}$ Epilepsy was the second most frequent diagnosis in our study, consistent with reports stating the disease as a common condition requiring OLDU. ${ }^{48}$ While lacosamide was among the most frequently requested drugs in child and adolescent groups (sixth and twelfth rank, respectively), it was beyond the $15^{\text {th }}$ rank in infants. This might suggest that physicians are unlikely to prefer unapproved antiepileptics in younger patients even in the OLDU context. In addition, though a study reported its efficacy for refractory focal epilepsy, ${ }^{49}$ two studies in different European countries reported lower prescription rates of newer antiepileptics in infants than that in older children..$^{50-51}$ 
The main indication for OLDU practice in our study was "other pulmonary heart disease", encompassing primary and secondary pulmonary hypertension. Beside digoxin, calcium antagonists, anticoagulants, and oxygen therapy, the disease could also be managed with prostanoids, endothelin receptor antagonists, and phosphodiesterase inhibitors. ${ }^{52,53}$ Consistent with these, iloprost, sildenafil, and bosentan were the most commonly applied drugs for secondary pulmonary hypertension in our study. Moreover, a previous OLDU study in Turkey reported that these drug groups were most commonly requested for pulmonary hypertension in pediatric populations. ${ }^{26}$ It could be suggested that these drugs were subject to OLDU applications as they had limited clinical trial data on pediatric use. ${ }^{52}$ Among these agents, bosentan had been approval in pulmonary hypertensive $\geq 3$-year-old children in $\mathrm{US}^{54}$ and the summary product of bosentan in Turkey with a statement of limited experience in $<2$ years of age..$^{55}$ These might explain higher off-label use of bosentan in infants. On the other hand, sildenafil use was common in this age group whereas iloprost was found to dominate child and adolescent groups. In fact, the latter is approved for pulmonary hypertension in Turkey with a warning that stated it had no clinical data on pediatric use. ${ }^{56}$ Contrarily, sildenafil is only approved for erectile dysfunction. ${ }^{57}$ This difference of indication might partly explain preference of iloprost over sildenafil in older age groups. Another factor could be the warning on sildenafil's FDAapproved pulmonary hypertension label that recommends against chronic use in pediatric cases due to increased mortality concerns. ${ }^{58}$

Our findings should be interpreted in the light of several limitations. First, we did not have information on medication history regarding the diagnoses that required OLDU or currently used drugs for accompanying diseases. Diminished efficacy or adverse effects due to concomitant medication might have forced physicians toward OLDU practice. In addition, we did not collect data on how many OLDU applications were made for a particular indication regarding same/different drugs with no further information about OLDU switches for the same indication. Another limitation was the lack of data on duration and posology of off-label drugs. Finally, this study only included OLDU requests that were approved by the health authority, excluding rejected applications and any other OLDU practiced with the physicians' own discretion.

In conclusion, this study is the first to show indication- and drug-centered aspects of pediatric OLDU at national level, exposing its similar and distinguishing features from routine prescribing practice. Though OLDU applications is overall consistent with routine clinical practice in terms of demographics and institutional capacity, substantial variations exist regarding main drug classes and diseases. Pediatric OLDU practice seems to converge on particular classes of drugs for certain indications that are rather encountered during childhood and usually required alternative pharmacotherapeutic options. Besides, pediatric OLDU appears to differ from that in adults in terms of indications and drugs. Our findings are expected to shed light on interventions focusing on increasing "indicated" use of off-label drugs and contribute to their rational use within the pediatric OLDU context, if inevitable.

\section{Acknowledgements}

The authors thank to Dr. Esra Onal for her contribution to the study design and Dr. Fatma Isli, Esma Kadi and other respective staff/ consultants of TMMDA for their assistance in data collection.

\section{Funding}

This work was supported by Research Fund of the Marmara University (Project Number: SAGC-DRP-150218-0034). 


\section{REFERENCES}

1. Woodcock J, Woosley R. The FDA critical path initiative and its influence on new drug development. Annu Rev Med 2008; 59: 1-12.

2. Budetti PP. Ensuring safe and effective medications for children. JAMA 2003; 290: 950-951.

3. Cerreta F, Eichler HG, Rasi G. Drug policy for an aging population-the European Medicines Agency's geriatric medicines strategy. N Engl J Med 2012; 367: 1972-1974.

4. T.C. Sağlık Bakanlığı Türkiye İlaç Tıbbi Cihaz Kurumu. Endikasyon Dışı İlaç Kullanım Kılavuzu, 09.02.2019. Available at: www.titck.gov.tr/storage/ Archive/2019/legislation/601621f0-2e3e-40d4-97cd65bef02b1a61.pdf (Date of access: 5th November 2020)

5. Frattarelli DA, Galinkin JL, Green TP, et al; American Academy of Pediatrics Committee on Drugs. Offlabel use of drugs in children. Pediatrics 2014; 133: 563-567.

6. Poole SG, Dooley MJ. Off-label prescribing in oncology. Support Care Cancer 2004; 12: 302-305.

7. Rayburn WF, Farmer KC. Off-label prescribing during pregnancy. Obstet Gynecol Clin North Am 1997; 24: 471478.

8. Mühlbauer B, Janhsen K, Pichler J, Schoettler P. Offlabel use of prescription drugs in childhood and adolescence an analysis of prescription patterns in Germany. Dtsch Arztebl Int 2009; 106: 25-31.

9. Olsson J, Kimland E, Pettersson S, Odlind V. Pediatric drug use with focus on off-label prescriptions in Swedish outpatient care - a nationwide study. Acta Paediatr 2011; 100: 1272-1275.

10. Cuzzolin L, Zaccaron A, Fanos V. Unlicensed and off-label uses of drugs in pediatricpediatrics : a review of the literature. Fundam Clin Pharmacol 2003; 17: 125-131.

11. World Health Organization. Promoting safety of medicines for children. World Health Organization, 2007.

12. Kimland E, Odlind V. Off-label drug use in pediatric patients. Clinical Pharmacol Ther2012; 91: 796-801.

13. de Souza AS Jr, Dos Santos DB, Rey LC, Medeiros MG, Vieira MG, Coelho HLL. Off-label use and harmful potential of drugs in a NICU in Brazil: a descriptive study. BMC Pediatr 2016; 16: 13.

14. Moulis F, Durrieu G, Lapeyre-Mestre M. Off-label and unlicensed drug use in children population. Therapie 2018; 73: 135-149.
15. Oguz SS, Kanmaz HG, Dilmen U. Off-label and unlicensed drug use in neonatal intensive care units in Turkey: the old-inn study. Int J Clin Pharm 2012; 34: 136-141.

16. Aksoy M, Alkan A, Isli F. Rational drug use promotional activities of Ministry of Health. Türkiye Klin J Pharmacol-Special Top 2015; 3: 19-26.

17. Turkish Statistical Institute. Turkish Statistical System and Turkstat Istanbul Regional Office. Study Visit of the UNSD, ESCAP and OSCE to Turkey, 17 Sep 2015, İstanbul. Available at: https://unstats.un.org/unsd/ demographic/meetings/wshops/Turkey/2015/docs/ Presentations/Session15-Turkstat_overview_ENG. pdf (Date of access: 28th August 2020).

18. The Ministry of Health of Turkey. Turkey Health Statistics Yearbook 2015. Ankara, 2016.

19. T.C. Kalkınma Bakanlığı. İllerin ve Bölgelerin Sosyo-Ekonomik Gelişmişlik Sıralaması Araştırması (SEGE-2011) [Ministry of Development (Turkey), Survey of Socio-Economic Development Ranking of Provinces and Regions], Ankara, 2013.

20. Ministry of Interior. Number of People by Age in General Directorate of Civil Registration and Citizenship, 2018.

21. Nir-Neuman H, Abu-Kishk I, Toledano M, Heyman E, Ziv-Baran T, Berkovitch M. Unlicensed and offlabel medication use in pediatric and neonatal intensive care units: no change over a decade. Adv Ther 2018; 35: 1122-1132.

22. Dagnew AB, Tewabe T, Murugan R. Level of modern health care seeking behaviors among mothers having under five children in Dangila town, north West Ethiopia, 2016: a cross sectional study. Ital J Pediatr 2018; 44: 44-61.

23. Sahin A, Akici A, Aydin V, Melik B, Aksoy M, Alkan A. Variation of antibiotic consumption and its correlated factors in Turkey. Eur J Clin Pharmacol 2017; 73: 867-873.

24. Bayram D, Kırmızı NI, Özdamar EN, Bayar B, Gürsöz H, Akıc1 A. Investigation of the off-label drug use at provincial and regional levels. Gazi Med J 2018; 29: 312-318.

25. Masiero G, Filippini M, Ferech M, Goossens H. Socioeconomic determinants of outpatient antibiotic use in Europe. Int J Public Health 2010; 55: 469-478.

26. Özdamar EN, Akici A, Alkan A, Bayar B, Gürsöz H. A nationwide evaluation of off-label drug utilization in Turkey. Turkish J Med Sci 2017; 47: 1229-1238. 
27. Stachnik J, Gabay M. Biologics in Pediatrics. In: Field MJ, Boat TT (eds). Safe and Effective Medicines for Children: Pediatric Studies Conducted Under the Best Pharmaceuticals for Children Act and the Pediatric Research Equity Act. Washington (DC): National Academies Press (US), 2012.

28. Yazılıtaş F, Aydoğ Ö, Özlü SG, et al. Canakinumab treatment in children with familial Mediterranean fever: report from a single center. Rheumatol Int 2018; 38: 879-885.

29. Sturkenboom MCJM, Verhamme KMC, Nicolosi A, et al; TEDDY European Network of Excellence. Drug use in children: cohort study in three European countries. BMJ 2008; 337: a2245.

30. Thrane N, Sørensen HT. A one-year populationbased study of drug prescriptions for Danish children. Acta Paediatr 1999; 88: 1131-1136.

31. Lindell-Osuagwu L, Hakkarainen M, Sepponen K, Vainio K, Naaranlahti T, Kokki H. Prescribing for off-label use and unauthorized medicines in three pediatric wards in Finland, the status before and after the European Union Pediatric Regulation. J Clin Pharm Ther 2014; 39: 144-153.

32. Palmaro A, Bissuel R, Renaud N, et al. Off-label prescribing in pediatric outpatients. Pediatrics 2015; 135: 49-58.

33. Walsh PR, Johnson S. Treatment and management of children with haemolytic uraemic syndrome. Arch Dis Child 2018; 103: 285-291.

34. Loirat C, Fakhouri F, Ariceta G, et al; HUS International. An international consensus approach to the management of atypical hemolytic uremic syndrome in children. Pediatr Nephrol 2016; 31: 1539.

35. Castañeda-Sanabria J, Hajage D, Le Jouan $M$, Perozziello A, Tubach F. Off-label use of the expensive orphan drug eculizumab in France 20092013 and the impact of literature: focus on the transplantation field. Eur J Clin Pharmacol 2016; 72: 737-746.

36. Turkish Medicines and Medical Devices Agency. Soliris (eculizumab) Summary of Product Characteristics. Available at: www.titck.gov.tr/ storage/Archive/2020/kubKtAttachments/SOLIRIS 300mg30mlkonsantreinfzyonzeltisikbtemiz_6e258c 8f-5ecd-4743-8d4c-64fc86a06331.pdf (Date of access: 5 th November 2020)

37. FDA. Cellcept (mycophenolate mofetil) Prescribing Information. 2019. Available at: www.accessdata. fda.gov/ drugsatfda_docs/ label/2019/050722s040, 050723s041, 050758s037, 050759s045lbl.pdf (Date of access: 5th November 2020)
38. Turkish Medicines and Medical Devices Agency. Cellcept (Mycophenolate mofetil) Summary of ProductCharacteristics.2019.Availableat:www.titck. gov.tr/storage/Archive/2020/kubKtAttachments/ TTCKCELLCEPT250MGKAPSLUYGUNKB bf50215d-3fbf-427b-bc7c-37427a9ff328.pdf (Date of access: 5th November 2020)

39. Downing HJ, Pirmohamed M, Beresford MW, Smyth RL. Pediatric use of mycophenolate mofetil. Br J Clin Pharmacol 2013; 75: 45-59.

40. Moudgil A, Bagga A, Jordan SC. Mycophenolate mofetil therapy in frequently relapsing steroiddependent and steroid-resistant nephrotic syndrome of childhood: current status and future directions. Pediatr Nephrol 2005; 20: 376-1381.

41. Chen Y, Li YM, Yang SL, Li Y, Liang M. Efficacy and safety of mycophenolate mofetil treatment in IgA nephropathy: a systematic review. BMC Nephrol 2014; 15: 193.

42. Zhao Z, Liao G, Li Y, Zhou S, Zou H. The efficacy and safety of rituximab in treating childhood refractory nephrotic syndrome: a meta-analysis. Sci Rep 2015; 5: 8219 .

43. Ramos-Casals M, García-Hernandez FJ, de Ramón E, et al; BIOGEAS Study Group. Off-label use of rituximab in 196 patients with severe, refractory systemic autoimmune diseases. Clin Exp Rheumatol 2010; 28: 468-476.

44. King C, Logan S, Smith SW, Hewins P. The efficacy of rituximab in adult frequently relapsing minimal change disease. Clin Kidney J 2017; 10: 16-19.

45. Fenoglio R, Sciascia S, Beltrame G, et al. Rituximab as a front-line therapy for adult-onset minimal change disease with nephrotic syndrome. Oncotarget 2018; 9: 28799-28804.

46. FDA. Vimpat (Lacosamide) Summary of Product Characteristics, 2017. Available at: www.accessdata.fda.gov/drugsatfda_docs/ label/2017/022253s039,022254s030,022255s022lbl.pdf (Date of access: 5th November 2020)

47. Turkish Medicines and Medical Devices Agency. Benvida (Lacosamide) Summary of Product Characteristics. Available at: www.titck.gov. tr/storage/Archive/2019/kubKtAttachments/ yay $\%$ C4\%B1nlanacak-k\%C3\%BCb-benvida $\% 20$ $10 \% 20 \%$ C $4 \%$ B 1 v \% $20 \%$ C 3 \% A 7 \% C 3 \% B 6 z. pdf_6596367d-270f-46da-875a-1946e652d1fe.pdf (Date of access: 5th November 2020)

48. Dang LT, Silverstein FS. Drug treatment of seizures and epilepsy in newborns and children. Pediatr Clin North Am 2017; 64: 1291-1308. 
49. Grosso S, Parisi P, Spalice A, Verrotti A, Balestri P. Efficacy and safety of lacosamide in infants and young children with refractory focal epilepsy. Eur J Paediatr Neurol 2014; 18: 55-59.

50. Ackers R, Murray ML, Besag FMC, Wong ICK. Prioritizing children's medicines for research: a pharmaco-epidemiological study of antiepileptic drugs. Br J Clin Pharmacol 2007; 63: 689-697.

51. Dörks M, Langner I, Timmer A, Garbe E. Treatment of pediatric epilepsy in Germany: antiepileptic drug utilisation in children and adolescents with a focus on new antiepileptic drugs. Epilepsy Res 2013; 103: 45-53.

52. Abman SH, Hansmann G, Archer SL, et al; American Heart Association Council on Cardiopulmonary, Critical Care, Perioperative and Resuscitation; Council on Clinical Cardiology; Council on Cardiovascular Disease in the Young; Council on Cardiovascular Radiology and Intervention; Council on Cardiovascular Surgery and Anesthesia; and the American Thoracic Society. Pediatric pulmonary hypertension. Guidelines From the American Heart Association and American Thoracic Society. 2015; 132: 2037-2099.

53. Ivy D. Advances in pediatric pulmonary arterial hypertension. Curr Opin Cardiol 2012; 27: 70-81.

54. FDA. Tracleer (bosentan) Prescribing Information. 2018. Available at: www.accessdata.fda.gov/ drugsatfda_docs/label/2017/209279s000lbl.pdf (Date of access: 5th November 2020)
55. Turkish Medicines and Medical Devices Agency. Boselix (Bosentan) Summary of Product Characteristics. Available at: https://titck.gov.tr/ storage/kubKtAttachments/a1d30f7343713.pdf (Date of access: 5th November 2020)

56. Turkish Medicines and Medical Devices Agency. Ventavis (Iloprost) Summary of Product Characteristics. Available at: www.titck.gov. $\mathrm{tr} /$ storage/Archive/2019/kubKtAttachments/ K\%C3\%9CB-UYGUN.pdf_322ff534-5eb1-4ceb-b6890de98057453c.pdf (Date of access: 5th November 2020)

57. Turkish Medicines and Medical Devices Agency. Viagra (Sildenafil) Summary of Product Characteristics. Available at: www.titck.gov. tr/storage/Archive/2019/kubKtAttachments/ T \% C $4 \%$ B 0 T C K \% 20 On a y 1\% C $4 \%$ B $1 \% 20$ K\%C3\%9CB\%20VIAGRA\%20100\%20MG.pdf_ c1d43e3d-f471-4893-8bcf-7b4ba9d11fea.pdf (Date of access: 5th November 2020)

58. FDA. Revatio (sildenafil) Summary of Product Characteristics, 2014. Available at: www.accessdata.fda.gov/drugsatfda_docs/ label/2014/021845s011,022473s004,0203109s002lbl. pdf (Date of access: 5th November 2020) 